\title{
One Hundred Years of Insulin: Value Beyond Price in Type 2 Diabetes Mellitus
}

\author{
Marc Evans · Angharad R. Morgan · Stephen C. Bain
}

Received: March 11, 2021 / Accepted: April 12, 2021 / Published online: April 26, 2021

(c) The Author(s) 2021

\section{ABSTRACT}

Type 2 diabetes mellitus is a chronic, progressive disease that frequently necessitates treatment with basal insulin to maintain adequate glycaemic control. In considering the value of different basal insulin therapies, although acquisition costs are of increasing importance to budget-constrained healthcare systems, value beyond simple price considerations should be taken into account. Whilst human basal insulins are of lower acquisition cost compared to long-acting insulin analogues, this difference in price has the potential to be offset in terms of total healthcare system value through the ultralong duration of action and low variability in glucose-lowering activity which have been translated into real clinical benefits, in particular a reduced risk of hypoglycaemic events. The maintenance of glycaemic targets and avoidance of hypoglycaemia that have been associated with insulin analogues represent a

M. Evans $(\bowtie)$

Diabetes Resource Centre, University Hospital

Llandough, Cardiff, UK

e-mail: marclyndon1@hotmail.com

A. R. Morgan

Health Economics and Outcomes Research Ltd., Cardiff, UK

S. C. Bain

Diabetes Research Unit, Swansea University Medical

School, Swansea, UK significant value consideration, beyond price, for the use of basal insulin analogues to manage type 2 diabetes mellitus from the perspective of all stakeholders within the healthcare system, including payers, healthcare professionals, patients and society.

Keywords: Health care costs; Health expenditures; Human insulin; Insulin analogue; Type 2 diabetes mellitus 


\section{Key Summary Points}

Drug acquisition costs are of increasing importance to budget-constrained healthcare systems.

Whilst human basal insulins for the management of type 2 diabetes mellitus are of lower acquisition cost compared to long-acting insulin analogues, it is important to consider value beyond price and to take into account the wider costs associated with insulin use over the full cycle of care and across the entire healthcare system.

The health impact of glycaemic control, hypoglycaemia, weight gain and ease of treatment represents a significant value consideration, beyond price, for the use of basal insulin analogues to manage type 2 diabetes mellitus from the perspective of all stakeholders within the healthcare system, including payers, healthcare professionals, patients and society.

\section{DIGITAL FEATURES}

This article is published with digital features, including a summary slide, to facilitate understanding of the article. To view digital features for this article go to https://doi.org/10.6084/ m9.figshare.14401307.

\section{BACKGROUND}

Diabetes is a growing global public health concern, with patient numbers quadrupling over the past three decades [1]. The growing prevalence of diabetes is thought to be related to increases in the prevalence of risk factors, such as obesity, cardiovascular disease, hypertension and prediabetes, alongside an aging population $[2,3]$. In addition to changes in the prevalence of risk factors, increases in screening, as well as changes in diagnostic criteria, may also contribute to the growing number of people with diabetes.

It has been estimated that there are now approximately 425 million adults (1 in 11) living with diabetes worldwide, $90 \%$ of whom have type 2 diabetes mellitus (T2DM) [4, 5]. The increasing prevalence of diabetes translates into increasing costs for healthcare providers. The 2018/2019 UK National Health Service (NHS) digital report calculated NHS costs of treating diabetes at $£ 1.07$ billion for this period, which was significantly more than for any other health condition [6]. In addition, the report highlighted that diabetes accounted for $13 \%$ of total prescribing costs across England [6]. The increasing prescribing costs associated with diabetes is likely to continue, reflecting both the rising number of people diagnosed with diabetes and the large increases in acquisition costs of diabetes treatments, such as insulin.

The NHS has been under increasing financial pressure from a growing chronic disease burden, particularly diabetes, for several years. In the current climate, with the coronavirus disease 2019 (COVID-19) pandemic, the financial pressures have further increased, and the consequences and costs are likely to be felt for many years. As a result, there are increasing requirements from payers and decision-makers to use resources wisely to get better value from the NHS budget. Consequently, diabetes treatments should be assessed in terms of outcomes and cost across the full cycle of care, including a robust focus on value from the perspective of all stakeholders within the healthcare system.

This article is based on previously conducted studies and does not contain any studies with human participants or animals performed by any of the authors.

\section{INSULIN IN T2DM}

Glycaemic control is the foundation of managing T2DM, and is essential to reduce the risk of macrovascular and microvascular complications associated with this condition [7]. To achieve normoglycaemia, most people with T2DM are initially managed with lifestyle modifications 
$[8,9]$. However, for many individuals diet and exercise alone are not sufficient to maintain glycaemic control and oral antidiabetic drugs (e.g. metformin, sulfonylureas, pioglitazone, acarbose, dipeptidyl peptidase IV inhibitors, sodium-glucose transport protein 2 inhibitors) and/or injected treatments (glucagon-like peptide 1 receptor agonists) will be required. Over time these therapies can become less effective, which may result in a worsening of glycaemic control for a significant proportion of people [10-12]. In such circumstances, the addition of insulin therapy to the treatment regimen is required to achieve optimal blood glucose targets $[13,14]$. There are many different approaches to insulin initiation; however, in many healthcare systems initiation with a basal insulin is the preferred approach in people with T2DM.

Since the discovery of insulin in 1921 [15] there have been major advances in the production of insulin [16]. Initial insulin preparations were from animal sources and although successful as a diabetes treatment, they were associated with side effects such as insulin allergy and lipoatrophy [17]. The development of synthetic and recombinant human insulins provided greater purity as well as reproducibility of response and reduced the risk of insulin allergy and lipoatrophy, although hypoglycaemia remained a common adverse effect [18]. Basal insulin analogues were developed to provide a more physiologic pharmacokinetic/ pharmacodynamic profile with longer duration, less intra-patient variability, less pronounced peak in time-action profiles and decreased hypoglycaemic risk compared with human insulins [19]. Advances in recombinant DNA technology have led to further improvements in insulin pharmacology, with the most recently developed second-generation longer-acting basal insulin analogues having a more stable, ultra-long duration of action enabling oncedaily administration with flexibility of injection time and a further reduction in the risk of hypoglycaemia [20].

Basal long-acting insulin analogues are now a major cost consideration in the management of diabetes as they have a substantially higher acquisition cost than basal human insulin. The annual cost of insulin analogues for the NHS increased from $£ 18.2$ million in 2000 to $£ 305$ million in 2009 [21], and it was estimated that if all dispensations for insulin analogues during this period had used a human insulin alternative, the NHS would have saved an estimated $£ 625$ million [21]. Many healthcare providers do not consider the higher acquisition costs of insulin analogues to correspond to an equivalent extra clinical benefit, and thus promote the switching of analogue to human basal insulin. In the National Institute for Health and Care Excellence (NICE) guidance for the management of people with T2DM, the use of human basal insulin is recommended as first-line insulin therapy, and long-acting basal analogues are only recommended in certain specific circumstances [22]. There have been suggestions that switching from basal analogue to human insulin therapy may be cost saving. However, even though starting people with T2DM on human insulin, or converting people from insulin analogues, is likely to reduce health expenditure, this may be an over-simplification of the economic value of insulin treatments. When considering the value of insulin, it is important to appreciate the totality of the cost implications associated with insulin therapy in people with T2DM and to include insulin resource use beyond acquisition costs, such as patient education, glucose self-monitoring, productivity costs and potential healthcare service (e.g. general practitioner visits, emergency room visits and hospitalisations). All of these financial considerations need to be set in the context of the health impact of glycaemic control, hypoglycaemia, weight gain and ease of treatment to determine the true value of the insulin treatment.

\section{VALUE OF INSULIN ANALOGUES IN T2DM}

In a retrospective cohort study evaluating the switching of people with T2DM from analogue to human insulin, individuals that switched to human insulin were found to have an overall $0.14 \%$ increase in glycated haemoglobin (HbA1c) compared to those who did not switch 
insulins [23]. Although the change in HbA1c observed in this study is small, and for most individuals would not be clinically significant, it is likely that if the study were to be carried out for longer and/or in a larger group of people this change associated with human insulin could be magnified and may have a detrimental effect on the risk of microvascular events; a number of studies have highlighted an increased risk of complications with increasing HbA1c levels [24-26]. Modest improvements in glycaemic control have the potential to generate significant reductions in the incidence, and therefore cost, of complications in people with T2DM [27]. It has previously been estimated that implementation of achievable, incremental improvements in glycaemic control, and the associated reduction in complication rates, could result in a significant cost avoidance over 5 years of approximately $£ 340$ million to the UK healthcare system, increasing to $£ 5.5$ billion after 25 years of sustained improvement in glycaemic control [28].

The rationale for basal insulin analogues producing superior levels of glycaemic control compared with human insulin in routine clinical practice is likely to be related to the reduced burden of hypoglycaemia associated with

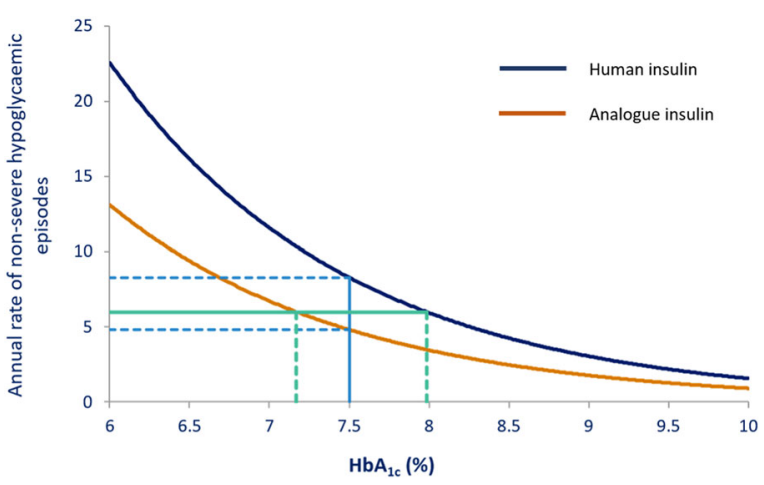

Fig. 1 Relationship between glycated haemoglobin (HbAlc) and hypoglycaemia. Blue line: for healthcare professionals, insulin analogues reduce the rates of hypoglycaemia at the target HbAlc level (e.g. 7.5\%). Green line: for patients, insulin analogues provide better glycaemic control at an acceptable level of hypoglycaemia (e.g. 6 per year). Figure is informed by a study characterising the frequency of severe and non-severe hypoglycaemia in insulin-treated people with type 2 diabetes mellitis [71] insulin analogues. Fear of hypoglycaemia from both the patient and healthcare professional perspective represents a significant barrier to insulin dose titration, and thus the achievement of good glucose control. Therefore, the preferential use of analogue as opposed to human basal insulin has the potential to promote better glucose control and reduce the burden of hypoglycaemia (Fig. 1).

The utility of basal insulin analogues compared with basal human insulin has been demonstrated in a variety of clinical trials reporting longer duration of action, less variability, more predictability, less hypoglycaemia (especially nocturnal) and a favourable effect on weight with basal insulin analogues [29-31]. Furthermore, the advantages of insulin analogues over human insulin in terms of reduced hypoglycaemia were supported by evidence from a recent Cochrane review [32], as well as a real-world study of 575,008 patients initiating use of insulin, in which it was demonstrated that long-acting insulin analogues were associated with a lower risk of emergency department visits or hospitalisations for hypoglycaemia compared with human insulin [33]. The reduced burden of hypoglycaemia represents a significant value consideration for the use of basal insulin analogues from the perspective of all stakeholders within the healthcare system, including payers, healthcare professionals, patients and society.

\section{Value of Basal Insulin Analogues to Payers}

The economic value of basal insulin analogues remains a point of contention as insulin analogues have a higher acquisition cost compared to human insulin, and clinical trials designed as treat-to-target studies have demonstrated similar levels of glucose control with the different insulin types. However, within these studies a consistent finding has been a lower rate of hypoglycaemia, in particular nocturnal hypoglycaemia, as well as quality of life increments in favour of the long-acting insulin analogues [34-38]. The reduced potential for nocturnal hypoglycaemia with basal insulin analogues represents a particularly important value 
consideration as nocturnal hypoglycaemia is typically associated with the greatest reduction in quality of life and is a major barrier to optimal therapy titration [39]. It may be argued that the differential rate of hypoglycaemia observed between insulin analogues and human insulin could be addressed through patient education strategies and optimised clinical pathways. However, even in a randomised controlled trial setting where clinical management is optimised, there is a persistent advantage with analogues for reduced hypoglycaemia, and this effect is likely to be amplified in a real-world setting.

Hypoglycaemia, particularly when severe (requiring third-party assistance), can result in significant healthcare resource utilisation considerations, such as general practitioner attendance, ambulance transport, accident and emergency care and hospital admission. A realworld analysis of approximately 4000 patients with diabetes who had a severe hypoglycaemic event reported that in the month following hypoglycaemia patients experienced significantly more frequent and prolonged hospital admissions and outpatient visits compared to the month prior to the hypoglycaemia event [40]. Hypoglycaemia therefore represents a substantial economic burden to healthcare providers, with significant costs associated with severe episodes requiring hospitalisation [41-43]. Severe hypoglycaemia is often assumed to have a greater economic impact than that of non-severe hypoglycaemia due to the higher costs associated with severe episodes. However, the annual costs of non-severe episodes of hypoglycaemia should not be overlooked. Due to the greater frequency of non-severe hypoglycaemia, it is likely to be associated with a similar or greater economic burden which is not fully appreciated. Furthermore, following a hypoglycaemic event it is recognised that there is an increase in glucose self-monitoring, representing an additional cost consideration associated with hypoglycaemia [44]. It has previously been estimated that the cost of a hypoglycaemic episode to the NHS health system can range from $£ 1.67$ for non-severe episodes (cost of using 6.2 extra blood glucose tests after a hypoglycaemic episode) to $£ 2152$ for severe episodes (for which the patient is admitted to hospital, requires an ambulance and uses the accident and emergency department), translating to annual costs of $£ 295.9$ million and $£ 172.1$ million for severe and non-severe episodes, respectively [45].

An economic model assessing the contribution of hypoglycaemia to changes in qualityadjusted life-years (QALYs) reported that QALYs ranged from -0.07 to +0.089 for $\mathrm{a}-30$ to + $30 \%$ change in the frequency of hypoglycaemia [46]. This relatively modest impact of changing hypoglycaemia frequency on QALYs is a result of the low reported rates of hypoglycaemia in the source data used in this study. However, in clinical practice, the impact of changes in hypoglycaemia frequency is expected to be greater as the true prevalence of symptomatic hypoglycaemia in patients receiving insulin is likely to be higher.

Long-acting insulin analogues have been associated with greater time in range (the percentage of time glucose levels are within 70-180 mg/dL (3.9-10 mmol/L) [47]) compared to human insulin [48]. As time in range has been shown to be inversely correlated to the risk of developing microvascular and macrovascular complications $[49,50]$, the reduction of these complications via improved maintenance of glycaemic stability associated with the use of insulin analogues, albeit conceptual, may translate into long-term health and economic benefits.

The number of frail, older people with diabetes is increasing, many of whom have multiple comorbidities, such as arthritis, tremor, vision impairment and dementia, complicating insulin self-administration and translating into a reliance on community care providers to administer insulin injections. As insulin analogues have a longer, more predictable pharmacological profile, compared to human insulin, they are more amenable to once-daily administration, consequently reducing the burden of care and thus costs associated with supported insulin administration.

It is important to appreciate that from the perspective of a healthcare system payer, the cost of insulin represents only a small proportion of the total health economic impact and 
that due to their direct healthcare cost consequences all of the factors described above should be considered when prescribing insulin. The potential cost offset, from the wider healthcare system perspective, of basal analogue insulin as opposed to basal human insulin was illustrated in a budget impact assessment in which the total annual expenditure associated with human insulin was found to be $8 \%$ higher at an individual level compared to insulin analogues, once all relevant costs were factored into the analysis [51]. The results of this study demonstrated that whilst insulin analogues have a higher acquisition cost than human insulins, this cost differential was offset by savings made in blood glucose monitoring costs, additional costs related to suboptimal insulin dosing and therapy non-adherence following hypoglycaemia and the direct healthcare costs associated with hypoglycaemia [51].

\section{Value of Basal Insulin Analogues to Healthcare Professionals}

The superior pharmacological profile of both first- and second-generation basal insulin analogues compared to human basal insulin has a value implication from the perspective of healthcare professionals involved in the management of people with T2DM treated with insulin. Insulin analogues are typically dosed once daily, whilst human insulin will often require more frequent dosing [20]. This will have implications for resource use from the perspective of healthcare professional time whilst also exerting a significant cost implication in terms of consumable use.

Increased hypoglycaemia burden associated with human insulin in terms of severe, nonsevere, daytime and, in particular, nocturnal hypoglycaemia, whilst associated with obvious patient health-related quality-of-life (HRQoL) issues will also have significant implications for the healthcare professional. This will manifest in terms of increased patient-healthcare professional contacts, an increase in the need for patient education regarding hypoglycaemia mitigation and management strategies and an increase in the prescription and use of glucose self-monitoring, which clearly has a cost implication for the healthcare system.

Hypoglycaemia represents a major barrier to therapy intensification and thus the achievement of glucose control. The use of human insulin with its associated increased hypoglycaemia risk therefore represents a significant burden and challenge to the healthcare professional in terms of addressing the issues of therapy non-adherence. The use of insulin analogues, which are associated with a lower rate of hypoglycaemia, may aid in addressing the concerns from the healthcare professional perspective around dose titration, and thus contribute to an improvement in glucose control.

The use of basal human insulin is likely to translate into a greater degree of variability in terms of patient glucose profiles [19]. This may impact on patient confidence in the therapy and on quality of life, increase the risk of hypoglycaemia and provide a further barrier to dose titration, consequently resulting in an increased potential for glucose self-monitoring. All these factors are significant considerations in terms of the healthcare professional support and education required for patients using human insulin compared with insulin analogues. Consequently, there is a clear rational to consider basal insulin analogues as representing superior value in comparison to basal human insulin from a healthcare professional perspective.

\section{Value of Basal Insulin Analogues to Patients}

Based on their pharmacological profile, insulin analogues can potentially provide benefits in terms of glucose control and hypoglycaemia (Fig. 1). Hypoglycaemia exerts a major impact on the HRQoL of people with T2DM, with short-term effects related to the symptoms associated with the actual episode and longerterm effects of fear and anxiety and sleep disturbance, as well as a negative impact on employment and leisure activities [52-57]. Posthoc analyses of the Action to Control Cardiovascular Risk in Diabetes (ACCORD) [58] and 
Action in Diabetes and Vascular Disease: Preterax and Diamicron MR Controlled Evaluation (ADVANCE) [59] trials reported a significant association between hypoglycaemia and mortality. Therefore, a reduction in the frequency of hypoglycaemia is one the key advantages of insulin analogues compared to human insulin for people with T2DM. In addition, a lower rate of hypoglycaemia has the potential to reduce out-of-pocket expenses from the patient perspective related to the need to travel to healthcare services for support following a hypoglycaemic episode.

Beyond the obvious advantage from a patient perspective of the reduced burden of hypoglycaemia, some insulin analogues are also associated with a reduction in weight gain compared to human insulin [31, 60]. Weight gain is well recognised to have detrimental effects related to HRQoL [61], as well as exerting wider implications in terms of healthcare resource use associated with the increased risk of developing comorbidities such as cardiovascular disease, cancer, chronic diseases, and depression, all of which have direct and indirect cost implications alongside detrimental effects on patient expectancy on quality and quantity of life [62-64].

The development of insulin analogues with a longer duration of action has enabled greater flexibility in the timing of insulin administration without an effect on either glucose control or hypoglycaemia risk [65]. Flexible dosing provides an obvious convenience and potential quality of life benefits to patients and may also translate into greater therapy adherence and hence improved glycaemic control. Furthermore, flexible insulin dosing may have significant implications for certain patient subgroups, the elderly in particular where assisted insulin administration is required.

\section{Value of Basal Insulin Analogues to Society}

With the increasing prevalence of T2DM translating into more patients progressing onto basal insulin therapy, the associated risk of hypoglycaemia has increasingly important societal implications, in particular those related to lost productivity. A Canadian survey-based retrospective observational study reported that after a severe hypoglycaemic event $32 \%$ of individuals went home from work/school and 26\% stayed home the following day, and that following a mild event $10 \%$ and $9 \%$ of individuals went home and stayed home the next day, respectively [53]. A survey assessing the impact of hypoglycaemia in 1404 individuals from the USA, UK, Germany and France estimated that a non-severe hypoglycaemic event resulted in 8.3-15.9 h of lost work time per month [66]. Interestingly, nocturnal hypoglycaemia was associated with the highest per-incident work time lost and costs for lost productivity [66]. In the 1-month prospective period of the Hypoglycaemia Assessment Tool (HAT) study, people with T2DM reported taking a mean 1.8 days off work or study due to hypoglycaemia [67].

The negative impact of hypoglycaemia can extend beyond the person with T2DM to family members/carers, who will often also have restrictions placed on their own health and well-being and on the dynamics of their relationship with the person with T2DM $[68,69]$. In the DAWN2 study, which included more than 2000 family members of people with diabetes, approximately one third of family members reported a notable burden and negative impact of diabetes, including effects on their emotional wellbeing, financial situation, leisure activities and physical health [70].

Based on the considerations discussed above, there is wider societal and economic value related to the reduced risk of hypoglycaemia associated with insulin analogues compared to human insulin, further highlighting the wider economic considerations related to analogue compared to human basal insulin use in people with T2DM.

\section{SUMMARY}

Due to the ever-increasing demand on limited healthcare resources, obtaining optimum value for medical therapies is essential. Basal insulin use in T2DM represents a significant economic consideration. 


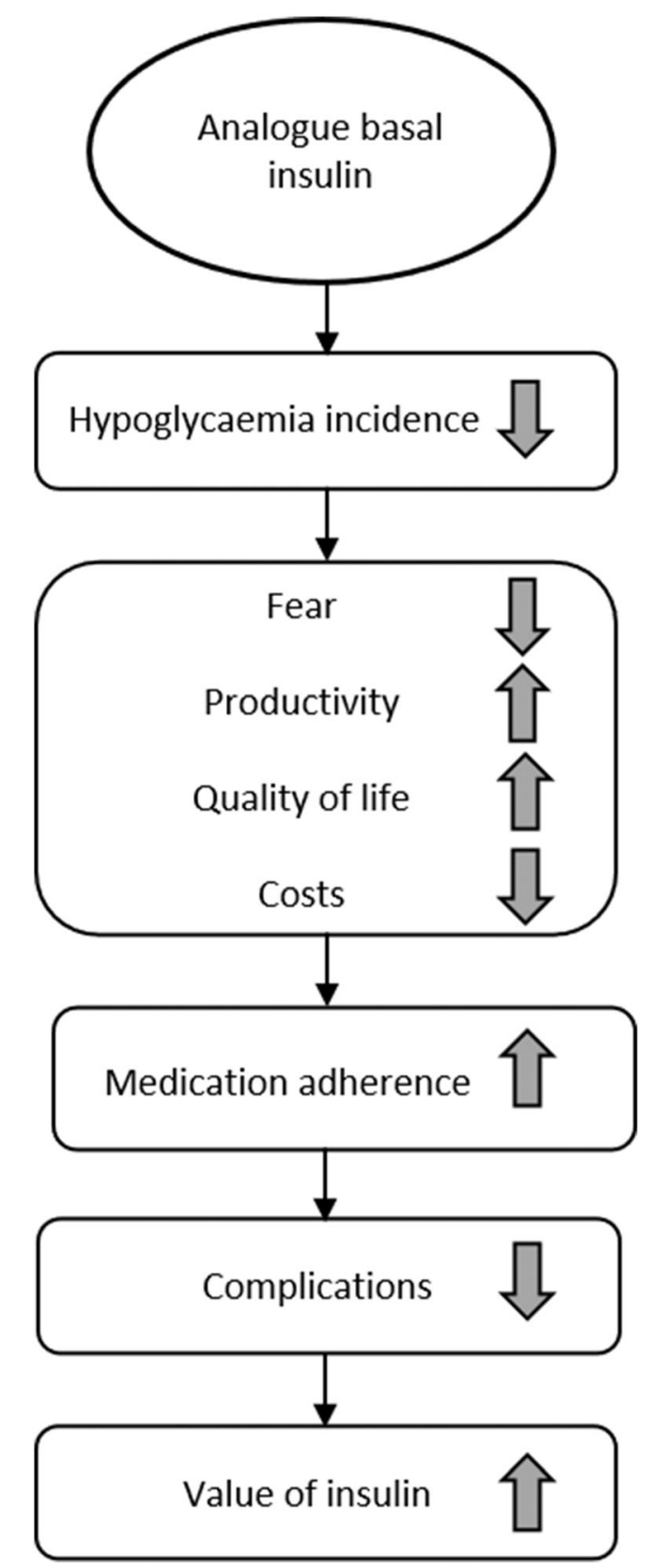

Fig. 2 The value of insulin analogues for payers, patients and society

Human insulin treatments are associated with a suboptimal duration of action, a marked peak effect and higher intra-individual variability, predisposing to increased risk of hypoglycaemia. Hypoglycaemia is associated with patient fear, a reduction in quality of life, lost productivity and reduced therapy adherence and titration and has direct healthcare costs consequences. As such, these considerations can significantly impact on the value of human insulin. In comparison, insulin analogues have no significant peak activity, a longer duration of action and less variability, which translates into a reduced risk of hypoglycaemia compared to human insulin. This reduced burden of hypoglycaemia will have a positive impact on the value of basal insulin analogue therapy in T2DM from the perspective of less patient fear, improved quality of life, less society cost consequences, better medication adherence and potentially longer-term glucose control with a reduced risk of complications (Fig. 2).

In conclusion, whilst human basal insulins are of lower acquisition cost compared to both first- and second-generation long-acting insulin analogues, the potential cost offset in terms of total healthcare system value from the perspective of the multiple stakeholders, including patients, payers, healthcare professionals and wider society, should be taken into account. It is likely that debate around the economics of insulin analogue use in T2DM will persist. A large, long-term, prospective real-world study evaluating the totality of costs, and value from the entire healthcare system, of people switching to human basal insulin regimens from analogues, as opposed to those continuing insulin analogues, would be very useful in further informing the debate. In any therapy area in routine clinical practice, it is imperative to consider value beyond product acquisition costs alone and to take into account the wider system-based costs. This is particularly exemplified with respect to analogue insulin use in people with T2DM, on which a considerable body of evidence exists to support the value of insulin analogues over the full cycle of care and across the entire healthcare system.

\section{ACKNOWLEDGEMENTS}

Funding. This manuscript was supported by a grant from Novo Nordisk in respect of publication costs. Novo Nordisk has not influenced 
the content of the publication, or been involved in the design, collection, analysis or reporting of the data presented. No Rapid Service Fee was received by the journal for the publication of this article.

Authorship. All named authors meet the International Committee of Medical Journal Editors (ICMJE) criteria for authorship for this article, take responsibility for the integrity of the work as a whole, and have given their approval for this version to be published.

Disclosure. Angharad R. Morgan is an employee of Health Economics and Outcomes Research Ltd., Cardiff, UK. Health Economics and Outcomes Research Ltd. received fees from Novo Nordisk in relation to this study. Marc Evans and Stephen C. Bain have nothing to disclose.

Compliance with Ethics Guidelines. This article is based on previously conducted studies and does not contain any studies with human participants or animals performed by any of the authors.

Data Availability. Data sharing is not applicable to this article as no datasets were generated or analysed during the current study.

Open Access. This article is licensed under a Creative Commons Attribution-NonCommercial 4.0 International License, which permits any non-commercial use, sharing, adaptation, distribution and reproduction in any medium or format, as long as you give appropriate credit to the original author(s) and the source, provide a link to the Creative Commons licence, and indicate if changes were made. The images or other third party material in this article are included in the article's Creative Commons licence, unless indicated otherwise in a credit line to the material. If material is not included in the article's Creative Commons licence and your intended use is not permitted by statutory regulation or exceeds the permitted use, you will need to obtain permission directly from the copyright holder. To view a copy of this licence, visit http://creativecommons.org/licenses/bync/4.0/.

\section{REFERENCES}

1. Zheng Y, Ley SH, Hu FB. Global aetiology and epidemiology of type 2 diabetes mellitus and its complications. Nat Rev Endocrinol. 2018;14(2):88-98.

2. Evans M, Morgan AR, Patel D, et al. Risk prediction of the diabetes missing million: identifying individuals at high risk of diabetes and related complications. Diabetes Ther. 2021;12(1):87-105.

3. Thibault V, Bélanger M, LeBlanc E, Babin L, Halpine $S$, Greene B, et al. Factors that could explain the increasing prevalence of type 2 diabetes among adults in a Canadian province: a critical review and analysis. Diabetol Metab Syndr. 2016;8:71.

4. International Diabetes Federation. IDF Diabetes Atlas, 9th edition 2019. http://www.diabetesatlas. org. Accessed 17 Feb 2021.

5. Scully $T$. Diabetes in numbers. Nature. 2012;485(7398):S2-3.

6. NHS Digital. Prescribing costs in hospitals and the community 2018-2019. 2019. https://digital.nhs. uk/data-and-information/publications/statistical/ prescribing-costs-in-hospitals-and-the-community/ 2018-2019. Accessed 17 Feb 2021.

7. Stolar M. Glycemic control and complications in type 2 diabetes mellitus. Am J Med. 2010;123(3 Suppl):S3-11.

8. Bantle JP, Wylie-Rosett J, Albright AL, et al. Nutrition recommendations and interventions for diabetes-2006: a position statement of the American Diabetes Association. Diabetes Care. 2006;29(9): 2140-57.

9. Schellenberg ES, Dryden DM, Vandermeer B, Ha C, Korownyk C. Lifestyle interventions for patients with and at risk for type 2 diabetes: a systematic review and meta-analysis. Ann Intern Med. 2013;159(8):543-51.

10. Karter AJ, Moffet HH, Liu J, et al. Glycemic response to newly initiated diabetes therapies. Am J Manag Care. 2007;13(11):598-606.

11. Turner RC, Cull CA, Frighi V, Holman RR. Glycemic control with diet, sulfonylurea, metformin, or insulin in patients with type 2 diabetes mellitus: progressive requirement for multiple therapies 
(UKPDS 49). UK Prospective Diabetes Study (UKPDS) Group. JAMA. 1999;281(21):2005-12.

12. Kahn SE, Haffner SM, Heise MA, et al. Glycemic durability of rosiglitazone, metformin, or glyburide monotherapy. N Engl J Med. 2006;355(23): 2427-43.

13. Inzucchi SE, Bergenstal RM, Buse JB, et al. Management of hyperglycemia in type 2 diabetes, 2015: a patient-centered approach: update to a position statement of the American Diabetes Association and the European Association for the Study of Diabetes. Diabetes Care. 2015;38(1):140-9.

14. Wright A, Burden AC, Paisey RB, Cull CA, Holman RR. Sulfonylurea inadequacy: efficacy of addition of insulin over 6 years in patients with type 2 diabetes in the UK. Prospective Diabetes Study (UKPDS 57). Diabetes Care. 2002;25(2):330-6.

15. Banting F, Best C. The internal secretion of the pancreas. J Lab Clin Med. 1922;7:251-71.

16. Tibaldi JM. Evolution of insulin development: focus on key parameters. Adv Ther. 2012;29(7):590-619.

17. Deckert T, Andersen OO, Poulsen JE. The clinical significance of highly purified pig-insulin preparations. Diabetologia. 1974;10(6):703-8.

18. Hirsch IB. Insulin analogues. $N$ Engl J Med. 2005;352(2):174-83.

19. Pieber TR, Treichel HC, Hompesch B, et al. Comparison of insulin detemir and insulin glargine in subjects with Type 1 diabetes using intensive insulin therapy. Diabet Med. 2007;24(6):635-42.

20. Mauricio D, Hramiak I. Second-generation insulin analogues-a review of recent real-world data and forthcoming head-to-head comparisons. Eur Endocrinol. 2018;14(Suppl1):2-9.

21. Holden SE, Poole CD, Morgan CL, Currie CJ. Evaluation of the incremental cost to the National Health Service of prescribing analogue insulin. BMJ Open. 2011;1(2):e000258.

22. National Institute for Health and Care Excellence. NICE guideline [NG28]. Type 2 diabetes in adults: management. 2015. https://www.nice.org.uk/ guidance/ng28. Accessed 17 Feb 2021.

23. Luo J, Khan NF, Manetti T, et al. Implementation of a health plan program for switching from analogue to human insulin and glycemic control among medicare beneficiaries with type 2 diabetes. JAMA. 2019;321(4):374-84.

24. Huang ES, Liu JY, Moffet HH, John PM, Karter AJ. Glycemic control, complications, and death in older diabetic patients: the diabetes and aging study. Diabetes Care. 2011;34(6):1329-36.

25. Clarke PM, Gray AM, Briggs A, et al. A model to estimate the lifetime health outcomes of patients with type 2 diabetes: the United Kingdom Prospective Diabetes Study (UKPDS) Outcomes Model (UKPDS no. 68). Diabetologia. 2004;47(10): 1747-59.

26. Hayes AJ, Leal J, Gray AM, Holman RR, Clarke PM. UKPDS outcomes model 2: a new version of a model to simulate lifetime health outcomes of patients with type 2 diabetes mellitus using data from the 30 year United Kingdom Prospective Diabetes Study: UKPDS 82. Diabetologia. 2013;56(9):1925-33.

27. Zoungas S, Arima H, Gerstein HC, et al. Effects of intensive glucose control on microvascular outcomes in patients with type 2 diabetes: a metaanalysis of individual participant data from randomised controlled trials. Lancet Diabetes Endocrinol. 2017;5(6):431-7.

28. Baxter M, Hudson R, Mahon J, et al. Estimating the impact of better management of glycaemic control in adults with Type 1 and Type 2 diabetes on the number of clinical complications and the associated financial benefit. Diabet Med. 2016;33(11): 1575-81.

29. Heinemann L, Linkeschova R, Rave K, Hompesch B, Sedlak M, Heise T. Time-action profile of the longacting insulin analog insulin glargine (HOE901) in comparison with those of NPH insulin and placebo. Diabetes Care. 2000;23(5):644-9.

30. Riddle MC, Rosenstock J, Gerich J. The treat-totarget trial: randomized addition of glargine or human NPH insulin to oral therapy of type 2 diabetic patients. Diabetes Care. 2003;26(11):3080-6.

31. Hermansen $\mathrm{K}$, Davies $\mathrm{M}$, Derezinski $\mathrm{T}$, Martinez Ravn G, Clauson P, Home P. A 26-week, randomized, parallel, treat-to-target trial comparing insulin detemir with NPH insulin as add-on therapy to oral glucose-lowering drugs in insulin-naive people with type 2 diabetes. Diabetes Care. 2006;29(6):1269-74.

32. Semlitsch T, Engler J, Siebenhofer A, Jeitler K, Berghold A, Horvath K. (Ultra-)long-acting insulin analogues versus NPH insulin (human isophane insulin) for adults with type 2 diabetes mellitus. Cochrane Database Syst Rev. 2020;11:CD005613.

33. Bradley MC, Chillarige $\mathrm{Y}$, Lee $\mathrm{H}$, et al. Severe hypoglycemia risk with long-acting insulin analogs vs neutral protamine Hagedorn insulin. JAMA Intern Med. 2021. 10.1001/jamainternmed.2020. 9176. 
34. Bi Y, Li X, Yang D, et al. Comparative efficacy and safety of long-acting insulin analogs in patients with type 2 diabetes failing on oral therapy: systemic review and meta-analyses. J Diabetes Investig. 2012;3(3):283-93.

35. Frier BM, Russell-Jones D, Heise T. A comparison of insulin detemir and neutral protamine Hagedorn (isophane) insulin in the treatment of diabetes: a systematic review. Diabetes Obes Metab. 2013;15(11):978-86.

36. Rys P, Wojciechowski P, Rogoz-Sitek A, et al. Systematic review and meta-analysis of randomized clinical trials comparing efficacy and safety outcomes of insulin glargine with NPH insulin, premixed insulin preparations or with insulin detemir in type 2 diabetes mellitus. Acta Diabetol. 2015;52(4):649-62.

37. Freemantle N, Chou E, Frois C, et al. Safety and efficacy of insulin glargine $300 \mathrm{u} / \mathrm{mL}$ compared with other basal insulin therapies in patients with type 2 diabetes mellitus: a network meta-analysis. BMJ Open. 2016;6(2):e009421.

38. Owens DR, Traylor L, Mullins P, Landgraf W. Patient-level meta-analysis of efficacy and hypoglycaemia in people with type 2 diabetes initiating insulin glargine $100 \mathrm{U} / \mathrm{mL}$ or neutral protamine Hagedorn insulin analysed according to concomitant oral antidiabetes therapy. Diabetes Res Clin Pract. 2017;124:57-65.

39. Edelman SV, Blose JS. The impact of nocturnal hypoglycemia on clinical and cost-related issues in patients with type 1 and type 2 diabetes. Diabetes Educ. 2014;40(3):269-79.

40. Goldstein D, Chodick G, Shalev V, Thorsted BL, Elliott L, Karasik A. Use of healthcare services following severe hypoglycemia in patients with diabetes: analysis of real-world data. Diabetes Ther. 2016;7(2):295-308.

41. Hammer M, Lammert M, Mejías SM, Kern W, Frier $\mathrm{BM}$. Costs of managing severe hypoglycaemia in three European countries. J Med Econ. 2009;12(4): 281-90.

42. Hex N, Bartlett C, Wright D, Taylor M, Varley D. Estimating the current and future costs of Type 1 and Type 2 diabetes in the UK, including direct health costs and indirect societal and productivity costs. Diabet Med. 2012;29(7):855-62.

43. McEwan P, Larsen Thorsted B, Wolden M, Jacobsen J, Evans M. Healthcare resource implications of hypoglycemia-related hospital admissions and inpatient hypoglycemia: retrospective recordlinked cohort studies in England. BMJ Open Diabetes Res Care. 2015;3(1):e000057.
44. Farmer A, Balman E, Gadsby R, et al. Frequency of self-monitoring of blood glucose in patients with type 2 diabetes: association with hypoglycaemic events. Curr Med Res Opin. 2008;24(11):3097-104.

45. Parekh WA, Ashley D, Chubb B, Gillies H, Evans M. Approach to assessing the economic impact of insulin-related hypoglycaemia using the novel local impact of hypoglycaemia tool. Diabet Med. 2015;32(9):1156-66.

46. McEwan $\mathrm{P}$, Evans $\mathrm{M}$, Kan $\mathrm{H}$, Bergenheim $\mathrm{K}$. Understanding the inter-relationship between improved glycaemic control, hypoglycaemia and weight change within a long-term economic model. Diabetes Obes Metab. 2010;12(5):431-6.

47. Beck RW, Bergenstal RM, Riddlesworth TD, et al. Validation of time in range as an outcome measure for diabetes clinical trials. Diabetes Care. 2019;42(3):400-5.

48. Evans M, Schumm-Draeger PM, Vora J, King AB. A review of modern insulin analogue pharmacokinetic and pharmacodynamic profiles in type 2 diabetes: improvements and limitations. Diabetes Obes Metab. 2011;13(8):677-84.

49. Lu J, Ma X, Zhou J, et al. Association of time in range, as assessed by continuous glucose monitoring, with diabetic retinopathy in type 2 diabetes. Diabetes Care. 2018;41(11):2370-6.

50. Gorst C, Kwok CS, Aslam S, et al. Long-term glycemic variability and risk of adverse outcomes: a systematic review and meta-analysis. Diabetes Care. 2015;38(12):2354-69.

51. Gordon J, Evans M, McEwan P, Bain S, Vora J. Evaluation of insulin use and value for money in type 2 diabetes in the United Kingdom. Diabetes Ther. 2013;4(1):51-66.

52. Frier BM. How hypoglycaemia can affect the life of a person with diabetes. Diabetes Metab Res Rev. 2008;24(2):87-92.

53. Leiter LA, Yale JF, Chiasson JL, Harris SB, Kleinstiver $\mathrm{P}$, Sauriol L. Assessment of the impact of fear of hypoglycemic episodes on glycemic and hypoglycemic management. Can J Diabetes. 2005;29: 186-92.

54. Lopez JM, Annunziata K, Bailey RA, Rupnow MF, Morisky DE. Impact of hypoglycemia on patients with type 2 diabetes mellitus and their quality of life, work productivity, and medication adherence. Patient Prefer Adherence. 2014;8:683-92.

55. Green AJ, Fox KM, Grandy S. Self-reported hypoglycemia and impact on quality of life and 
depression among adults with type 2 diabetes mellitus. Diabetes Res Clin Pract. 2012;96(3):313-8.

56. Currie CJ, Morgan CL, Poole CD, Sharplin P, Lammert M, McEwan P. Multivariate models of healthrelated utility and the fear of hypoglycaemia in people with diabetes. Curr Med Res Opin. 2006;22(8):1523-34.

57. Levy AR, Christensen TL, Johnson JA. Utility values for symptomatic non-severe hypoglycaemia elicited from persons with and without diabetes in Canada and the United Kingdom. Health Qual Life Outcomes. 2008;6:73.

58. Bonds DE, Miller ME, Bergenstal RM, et al. The association between symptomatic, severe hypoglycaemia and mortality in type 2 diabetes: retrospective epidemiological analysis of the ACCORD study. BMJ. 2010;340:b4909.

59. Zoungas S, Patel A, Chalmers J, et al. Severe hypoglycemia and risks of vascular events and death. N Engl J Med. 2010;363(15):1410-8.

60. Raslová K, Bogoev M, Raz I, Leth G, Gall MA, Hâncu N. Insulin detemir and insulin aspart: a promising basal-bolus regimen for type 2 diabetes. Diabetes Res Clin Pract. 2004;66(2):193-201.

61. Dennett SL, Boye KS, Yurgin NR. The impact of body weight on patient utilities with or without type 2 diabetes: a review of the medical literature. Value Health. 2008;11(3):478-86.

62. Thompson D, Edelsberg J, Colditz GA, Bird AP, Oster G. Lifetime health and economic consequences of obesity. Arch Intern Med. 1999;159(18): 2177-83.

63. Fontaine KR, Redden DT, Wang C, Westfall AO, Allison DB. Years of life lost due to obesity. JAMA. 2003;289(2):187-93.
64. Pi-Sunyer X. The medical risks of obesity. Postgrad Med. 2009;121(6):21-33.

65. Meneghini L, Atkin SL, Gough SC, et al. The efficacy and safety of insulin degludec given in variable once-daily dosing intervals compared with insulin glargine and insulin degludec dosed at the same time daily: a 26-week, randomized, open-label, parallel-group, treat-to-target trial in individuals with type 2 diabetes. Diabetes Care. 2013;36(4): 858-64.

66. Brod M, Christensen T, Thomsen TL, Bushnell DM. The impact of non-severe hypoglycemic events on work productivity and diabetes management. Value Health. 2011;14(5):665-71.

67. Khunti K, Alsifri S, Aronson R, et al. Impact of hypoglycaemia on patient-reported outcomes from a global, 24-country study of 27,585 people with type 1 and insulin-treated type 2 diabetes. Diabetes Res Clin Pract. 2017;130:121-9.

68. Rintala TM, Jaatinen P, Paavilainen E, Astedt-Kurki P. Interrelation between adult persons with diabetes and their family: a systematic review of the literature. J Fam Nurs. 2013;19(1):3-28.

69. Lawton J, Rankin D, Elliott J, et al. Experiences, views, and support needs of family members of people with hypoglycemia unawareness: interview study. Diabetes Care. 2014;37(1):109-15.

70. Nefs G, Pouwer F, Holt RI, et al. Correlates and outcomes of worries about hypoglycemia in family members of adults with diabetes: The second Diabetes Attitudes, Wishes and Needs (DAWN2) study. J Psychosom Res. 2016;89:69-77.

71. McEwan P, Foos V, Grant D, et al. Predicting the frequency of severe and non-severe hypoglycaemia in insulin treated type-2 diabetes subjects. Value Health. 2013;16:A435. 